\title{
Bronchial provocation determined by breath sounds compared with lung function
}

\author{
N Noviski, L Cohen, C Springer, E Bar-Yishay, A Avital, S Godfrey
}

\begin{abstract}
Bronchial provocation testing with methacholine was undertaken in 15 children aged 5 to 8 years with obstructive lung disease, mostly asthma (13/15). The methacholine was inhaled during two minutes of tidal breathing in increasing concentrations. After each inhalation, lung function was measured and clinical signs recorded independently by two observers unaware of each other's results. The logarithm of the concentration of methacholine which caused wheezing over the trachea correlated closely with the logarithm of the concentration of methacholine causing a $20 \%$ fall in the forced expiratory volume in one second $\left(F E V_{1}\right)$ but was $52 \%$ greater on average. At the end of the test there was a mean (SD) fall in FEV 1 of $33.3(7.4) \%$ and a fall in oxygen saturation of $5.2(3 \cdot 1) \%$. Bronchial provocation testing by listening for wheeze over the trachea is a safe technique, which correlates with objective measures of lung function in young children.
\end{abstract}

Methacholine challenge tests are commonly used for measuring bronchial reactivity in patients with clinical symptoms compatible with asthma. ${ }^{1-3}$ This usual method requires consistent patient cooperation in performing repeated maximal expiratory manoeuvres or plethysmography and is only practical for adults and older children. Recently, we described a modification of the conventional technique in which tracheal auscultation was used in children instead of measurement of lung functions. ${ }^{4}$ In that study we noted broad agreement between the concentration of methacholine causing wheezing (PCW) and that causing the forced expiratory volume in one second $\left(\mathrm{FEV} \mathrm{V}_{1}\right)$ to fall by $20 \%\left(\mathrm{PC}_{20}\right)$ in older children (aged 6-15 years, mean (SD) $10 \cdot 1(2 \cdot 9)$ ) able to perform both tests but these studies were not undertaken in a blind fashion. The present study was designed to investigate further this association in a properly controlled manner in the youngest cooperative children and to incorporate observations on other physical signs and oxygen saturation.

\section{Patients and methods}

The patients were 15 children aged 5 to 8 years with a mean (SD) of $7 \cdot 1(0.9)$ years. Their pertinent details, resting lung function, and transcutaneous oxygen saturation are listed in table 1. All but two of the children had asthma and all were being treated in the paediatric pulmonology clinic. The mean (SD) baseline $\mathrm{FEV}_{1}$ before the challenge was $92.9(11 \cdot 8) \%$ predicted and no child had a value below $72 \%$. Likewise no child was significantly hypoxic before the challenge with the mean (SD) saturation being $98(1.9) \%$. Bronchial provocation with methacholine was requested as part of their routine evaluation and parental consent was obtained. All children were cooperative enough to perform maximal forced expiratory manoeuvres consistently. The methacholine challenge procedure used was the tidal breathing method described by Cockcroft et $a^{1}$ during the course of which physical signs and saturation were recorded and lung function measured. The lung function measurements were performed by a trained pulmonary laboratory technician (LC) with experience in bronchial provocation testing in children. The chest auscultations were all performed by the same physician (NN) who is experienced in paediatric pulmonology.

Table I Anthropometric data, clinical diagnosis, and usual treatment

Department of
Paediatrics and the
Pulmonary Function
Laboratory, Hadassah
University Hospital,
Mount Scopus,
Jerusalem, Israel
N Novisky
L Cohen
C Springer
E Bar-Yishay
A Avital
S Godfrey
Correspondence to:
Professor S Godfrey,
Institute of Pulmonology,
Hadassah University Hospital,
Kiryat Hadassah, POB 12000,
Jerusalem, Israel.

Accepted 11 April 1991

\begin{tabular}{|c|c|c|c|c|c|c|c|}
\hline $\begin{array}{l}\text { Patient } \\
\text { No }\end{array}$ & $\begin{array}{l}\text { Age } \\
\text { (years) }\end{array}$ & $\begin{array}{l}\text { Weight } \\
\text { (kg) }\end{array}$ & $\begin{array}{l}\text { Height } \\
(\mathrm{cm})\end{array}$ & $\begin{array}{l}\text { Baseline } \\
F E V_{1} \text { (\%) }\end{array}$ & $\begin{array}{l}\text { Baseline } \\
\text { transcutaneous } \\
\text { oxygen } \\
\text { saturation (\%) }\end{array}$ & Diagnosis & Treatment ${ }^{*}$ \\
\hline $\begin{array}{l}1 \\
2 \\
3 \\
4 \\
5 \\
6 \\
7 \\
8 \\
9 \\
10 \\
11 \\
12 \\
13 \\
14 \\
15\end{array}$ & $\begin{array}{l}7 \\
8 \\
8 \\
7 \\
7 \\
5 \\
7 \\
8 \\
7 \\
8 \\
8 \\
6 \\
7 \\
7 \\
6\end{array}$ & $\begin{array}{l}26 \\
24 \\
27 \\
23 \\
22 \\
19 \\
23 \\
26 \\
26 \\
23 \\
35 \\
26 \\
23 \\
22 \\
17\end{array}$ & $\begin{array}{l}125 \\
126 \\
131 \\
119 \\
119 \\
116 \\
120 \\
126 \\
116 \\
126 \\
135 \\
120 \\
123 \\
121 \\
112\end{array}$ & $\begin{array}{r}83 \\
72 \\
75 \\
103 \\
85 \\
89 \\
97 \\
104 \\
96 \\
88 \\
89 \\
121 \\
96 \\
94 \\
101\end{array}$ & $\begin{array}{r}95 \\
98 \\
97 \\
98 \\
98 \\
99 \\
98 \\
100 \\
98 \\
100 \\
93 \\
100 \\
99 \\
97 \\
100\end{array}$ & $\begin{array}{l}\text { Asthma } \\
\text { Asthma } \\
\text { Bronchiectasis } \\
\text { Asthma } \\
\text { Immotile cilia syndrome } \\
\text { Asthma } \\
\text { Asthma } \\
\text { Asthma } \\
\text { Asthma } \\
\text { Asthma } \\
\text { Asthma } \\
\text { Asthma } \\
\text { Asthma } \\
\text { Asthma } \\
\text { Asthma }\end{array}$ & $\begin{array}{l}\text { T, B } \\
\text { T, S, B } \\
\text { B } \\
\text { B } \\
\text { B } \\
\text { T, B } \\
\text { B } \\
\text { C, B } \\
\text { T, S, B } \\
\text { T, S, B } \\
\text { S, B } \\
\text { C, B } \\
\text { B } \\
\text { S, B }\end{array}$ \\
\hline
\end{tabular}

${ }^{*} B$, inhaled $\beta_{2}$ sympathomimetic agents as needed; $T$, slow release theophylline preparations; $S$, inhaled corticosteroid preparations; and $\mathrm{C}$, sodium cromoglycate. 
PROTOCOL FOR INHALATION CHALLENGE TESTS All children avoided sympathomimetic bronchodilator treatment for at least eight hours before testing. Corticosteroids, slow release theophylline preparations, and sodium cromoglycate were continued unchanged. Details of medication are given in table 1 .

Methacholine was delivered during two minutes of quiet tidal breathing from a nebuliser (Hudson, Temecula) containing $2 \mathrm{ml}$ of test solution at the beginning of each inhalation. The aerosol was delivered into a face mask and inhaled through the mouth and nose. The nebuliser was driven by a compressor (Hand-EVent, Ohio Medical Products) with an output pressure of 15 psi yielding a rate of nebulisation of $0.20 \mathrm{ml} /$ minute.

The children performed spirometry using a pneumotachygraph based system (Vitalograph Compact Spirometer, Vitalograph Medical Instruments). The highest value of $\mathrm{FEV}_{1}$ from two technically satisfactory attempts was taken as the result. Measurements of baseline lung function were followed by two minutes inhalation of phosphate buffer solution (control). Spirometry was repeated after 30,90 , and 180 seconds. After this control inhalation, serial inhalations of doubling concentrations of methacholine were commenced, beginning with a concentration of $0.03 \mathrm{mg} / \mathrm{ml}$ and continuing every five minutes up to a maximal concentration of $16 \mathrm{mg} / \mathrm{ml}$. If the fall in $\mathrm{FEV}_{1}$ was between 15 and $20 \%$ the next increment in methacholine was by half the usual amount. For each concentration of methacholine, the measurements were performed as for the buffer solution.

Bronchial hyperreactivity by the standard method was defined as the methacholine concentration that caused a fall of $20 \%$ in $\mathrm{FEV}_{1}$ from the best value after the buffer solution $\left(\mathrm{PC}_{20}\right)$. The $\mathrm{PC}_{20}$ was read from a log response curve by linear interpolation.

Breath sound auscultation using a regular paediatric stethoscope was performed for approximately 30 seconds beginning about 15-30 seconds after each measurement of lung function while the children were breathing quietly. Auscultation was performed over the trachea and both lung bases. However, for the purposes of defining the end point note was taken only of wheezing clearly heard over the trachea. In addition, a note was made at the time of each clinical observation of the presence of cough, intercostal retractions, and crepitations over the lung fields. Heart rate and respiratory rate were recorded and oxygen saturation was measured continuously by pulse oximetry (Nellcor Inc) with the lowest value free from motion artefacts being taken as the result.

Both PC $_{20}$ and PCW were measured simultaneously, but in such a way that neither of the two investigators knew the results obtained by the other. The physician performed the auscultations without knowing the diagnosis, baseline lung function, the methacholine concentrations and the lung function post inhalation, and the technician did not know the clinical findings. It was decided before the study that the challenge should be halted when any one of the following conditions were met: (a) obvious wheezing heard over the trachea, (b) a methacholine concentration of $16 \mathrm{mg} / \mathrm{ml}$, (c) a fall in $\mathrm{FEV}_{1}$ greater than $50 \%$ from baseline, and (d) obvious dyspnoea. The methacholine concentration at which wheezing was first heard clearly over the trachea was taken as the result of the determination by auscultation (PCW). In the event, the end point of the challenge was wheezing heard over the trachea.

\section{STATISTICAL ANALYSIS}

Logarithmic transformation was used to describe the population results for $\mathrm{PC}_{20}$ and $\mathrm{PCW}$. Comparisons between the two methods of evaluation in the individual subjects were made using the paired Student's $t$ test.

\section{Results}

The individual results for $\mathrm{PC}_{20}$ and $\mathrm{PCW}$ are given in table 2 . For the group as a whole the numeric equivalent of the mean of the $\log \mathrm{PC}_{20}$ was $0.51 \mathrm{mg} / \mathrm{ml}$ with the mean +1 SD of 2.16 and the mean -1 SD of $0.12 \mathrm{mg} / \mathrm{ml}$. The equivalent values for the PCW was $0.81 \mathrm{mg} / \mathrm{ml}$ with +1 SD and -1 SD values of 3.32 and 0.20 $\mathrm{mg} / \mathrm{ml}$. The difference between the $\log P C_{20}$ and $\log P C W$ was significant $(p<0.001)$. The association between the $\mathrm{PCW}$ and the $\mathrm{PC}_{20}$ for the individual children plotted on a logarithmic scale is shown in the figure. There was an excellent correlation with the value for $r$ being 0.964 but the PCW values were higher than the

Table 2 Individual results of $P C W, P C_{20}$, and the clinical signs which appeared when the $P C W$ was reached

\begin{tabular}{|c|c|c|c|c|c|c|c|}
\hline $\begin{array}{l}\text { Patient } \\
\text { No }\end{array}$ & $\begin{array}{l}P C W \\
(m g / m l)\end{array}$ & $\begin{array}{l}P C_{20} \\
(m g / m l)\end{array}$ & $\underset{(\%)}{\Delta F E V_{I}^{*}}$ & $\begin{array}{l}\Delta \text { Respiratory }_{\text {rate }} \\
\left.\text { r }^{*} \%\right)\end{array}$ & $\begin{array}{l}\Delta \text { Hate }^{*}(\%) \\
\text { reart }^{\prime}\end{array}$ & $\begin{array}{l}\Delta \text { Oxygen } \\
\text { saturation* }\end{array}$ & Clinical signst \\
\hline $\begin{array}{r}1 \\
2 \\
3 \\
4 \\
5 \\
6 \\
7 \\
8 \\
9 \\
10 \\
11 \\
12 \\
13 \\
14 \\
15\end{array}$ & $\begin{array}{r}0.06 \\
0.18 \\
12.00 \\
0.50 \\
0.25 \\
1.00 \\
0.75 \\
1.50 \\
1.00 \\
0.25 \\
0.50 \\
8.00 \\
0.38 \\
6.00 \\
1.00\end{array}$ & $\begin{array}{l}0 \cdot 04 \\
0 \cdot 13 \\
6 \cdot 50 \\
0 \cdot 37 \\
0 \cdot 48 \\
0 \cdot 75 \\
0 \cdot 38 \\
0 \cdot 90 \\
0 \cdot 40 \\
0 \cdot 13 \\
0 \cdot 25 \\
6 \cdot 00 \\
0 \cdot 18 \\
5 \cdot 60 \\
0 \cdot 38\end{array}$ & $\begin{array}{l}-30 \\
-38 \\
-39 \\
-34 \\
-21 \\
-33 \\
-34 \\
-26 \\
-34 \\
-49 \\
-40 \\
-31 \\
-42 \\
-22 \\
-27\end{array}$ & $\begin{array}{r}4 \\
4 \\
18 \\
4 \\
28 \\
4 \\
4 \\
0 \\
8 \\
12 \\
4 \\
4 \\
12 \\
16 \\
0 \\
4\end{array}$ & $\begin{array}{c}-4 \\
10 \\
25 \\
10 \\
2 \\
7 \\
7 \\
8 \\
8 \\
7 \\
31 \\
1 \\
-2 \\
-2 \\
-9\end{array}$ & $\begin{array}{l}-4 \\
-1 \\
-9 \\
-3 \\
-8 \\
-8 \\
-2 \\
-8 \\
-6 \\
-2 \\
-3 \\
-3 \\
-8 \\
-2 \\
-11\end{array}$ & $\begin{array}{l}\text { TW } \\
\text { TW, LW, cough } \\
\text { TW, crepitations, cough } \\
\text { TW, } \\
\text { TW, } \\
\text { TW, crepitations, cough, retractions } \\
\text { TW, LW, retractions } \\
\text { TW, crepitations, cough } \\
\text { TW, LW, crepitations } \\
\text { TW, LW } \\
\text { TW, cough } \\
\text { TW, LW, cough } \\
\text { TW, cough } \\
\text { TW, LW, cough } \\
\text { TW, LW }\end{array}$ \\
\hline
\end{tabular}

*Change from baseline at PCW.

tTW, wheeze over trachea and $L W$, wheeze over lung fields. 


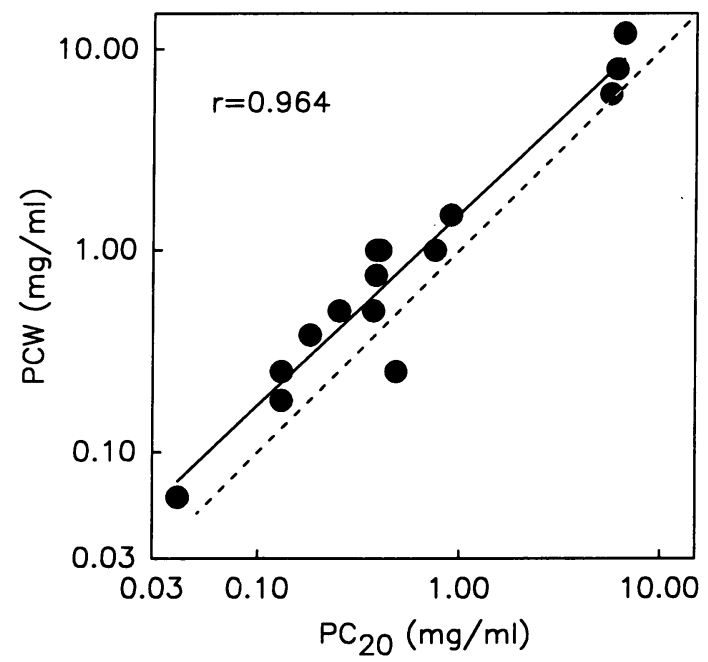

Association between $P C W$ and $P C_{20}$ in the individual children both plotted on logarithmic scales. The regression is shown by the solid line and the dashed line is the line of identity. The parallel shift of the regression line above the line of identity indicates that the $P C W$ is on average 1.52 times as great as the $P C_{20}$

$\mathrm{PC}_{20}$ values. The equation relating $\log \mathrm{PCW}$ to $\log \mathrm{PC}_{20}$ is:

$$
\log P C W=0.948 \times \log \mathrm{PC}_{20}+0 \cdot 182
$$

which implies that the association is virtually linear (exponent of 0.948 ) and that $\mathrm{PCW}=$ $\mathrm{PC}_{20} \times 1.52$ where 1.52 is the antilog of the intercept $0 \cdot 182$. The PCW was greater than $\mathrm{PC}_{20}$ in all but one child (table 2) and the mean (SD)\% fall in $\mathrm{FEV}_{1}$ at the methacholine concentration at which wheezing was first detected was $33 \cdot 3(7 \cdot 4)$.

The physical signs and changes in respiratory and heart rates and oxygen saturation found on auscultation at the methacholine concentration at which wheezing appeared are also listed in table 2 . The respiratory rate increased from baseline values by a mean of 8 breaths/minute (range 0-28) but only three children had a rise of more than 12 breaths/minute. Heart rate increased in 10 children, the maximum increase observed being 31 beats/minute, and decreased in the remaining five children with an overall mean rise in heart rate of 7 beats/minute. In eight children mild coughing had appeared coincidental with the wheezing, two developed mild retractions, and crepitations were heard in four. Oxygen saturation showed a mean (SD) decrease of $5 \cdot 2(3 \cdot 1) \%$ from the baseline value after the buffer inhalation. The lowest oxygen saturation recorded in any child was $\mathbf{8 8 \%}$. In all but one instance, where the oxygen saturation fell below $93 \%$, there was an increase in the respiratory rate by more than 30 breaths/minute. In the one child, where the saturation fell to $89 \%$ but the respiratory rate only rose by 24 breaths/minute, there was obvious dyspnoea. All of the physical signs, changes in oxygen saturation, and changes in lung function responded promptly to the inhalation of salbutamol. There was no correlation between the changes in respiratory rate, heart rate, or oxygen saturation and either the PCW or the
$\mathrm{PC}_{20}$. In some patients mild wheezing over the lung fields, localised crepitations, or transient coughing appeared before audible wheezing over the trachea but these signs did not correlate with either the final PCW or the $\mathrm{PC}_{20}$.

\section{Discussion}

This study has shown a high correlation between $\mathrm{PC}_{20}$ and PCW measured simultaneously in young children aged 5 to 8 years. In our previous study of children, who were on average three years older, we showed that the detection of tracheal wheezing by different observers was quite good with $80 \%$ complete agreement. ${ }^{4}$ The results serve to validate further the method of bronchial provocation testing by means of tracheal auscultation for use in young children unable to cooperate with routine tests of lung function. The PCW induces a fall in $\mathrm{FEV}_{1}$ of more than $20 \%$ on average. However, neither the severity of the obstruction nor the mild hypoxia in some patients was of any clinical significance and in no instance did the test result in anything more than mild, transient discomfort. In order to compare the severity of the airways obstruction when wheezing was first heard with that normally encountered at the end of a standard metacholine challenge to determine the $\mathrm{PC}_{20}$, we examined the data from another 10 children of simliar age who had undergone a standard challenge. In these 10 children, whose mean equivalent of the $\log \mathrm{PC}_{20}$ $(0.47 \mathrm{mg} / \mathrm{ml})$ was very similar to that in the present study, the mean (SD) of the fall in $\mathrm{FEV}_{1}$ at the end of their challenge was $30.6(6.7) \%$ which was not significantly different from the fall in $F E V_{1}$ in the present study at the conclusion of the challenge when wheezing was heard.

A decrease in transcutaneous oxygen tension in response to the inhalation of methacholine has been suggested by Mochizuki et al as a method of measuring bronchial reactivity as a result of a study in children with a mean age of 11 years. ${ }^{5}$ They showed a good correlation between the methacholine concentration causing the first fall in transcutaneous oxygen tension and that causing the first rise in respiratory resistance. However, as they did not relate their observations to any other measure of bronchial reactivity or to the clinical condition of their patients it is difficult to evaluate the method they described. In the present study the decrease in oxygen saturation was small and did not correlate well with the $\mathrm{PC}_{20}$ or the reduction of $\mathrm{FEV}_{1}$. To date we have performed over 300 tests using this method and have not needed to administer oxygen or give any additional treatment besides one inhalation of a $\beta$ agonist bronchodilator at the end of the test.

In our previous study in older children we noted that in three out of the 10 patients the test had to be stopped because the $\mathrm{FEV}_{1}$ had fallen by more than $20 \%$ before any wheezing had appeared. ${ }^{4}$ In other children studied in this laboratory (personal observations) we also noted that the $\mathrm{PCW}$ was greater than the $\mathrm{PC}_{20}$ for asthma of similar severity. Thus comparing the PCW in 17 asthmatic children aged 6-8 years 
old with the $\mathrm{PC}_{20}$ in 34 asthmatic children of similar age and asthma severity, we found that the ratio $\mathrm{PCW}: \mathrm{PC}_{20}$ was $1 \cdot 39$. In the present study the ratio $\mathrm{PCW}: \mathrm{PC}_{20}$ was similar $(1 \cdot 52)$ for simultaneous measurements in the same children. When using the stepwise doubling concentration technique for bronchial provocation with methacholine, the greater concentration for the PCW represents one half step more than that for the $\mathrm{PC}_{20}$.

In the standard steady state method of bronchial provocation described by Cockcroft and colleagues, ${ }^{1}$ which we used for our study, the results are expressed as the methacholine concentration causing a $20 \%$ fall in FEV $\left(\mathrm{PC}_{20}\right)$. Some investigators prefer to express the results as the total cumulative dose of methacholine received $\left(\mathrm{PD}_{20}\right)$. We therefore also calculated this parameter and the equivalent for the wheeze provocation study (PDW) and found that the correlation between them was very similar to that between $\mathrm{PC}_{20}$ and $\mathrm{PCW}$ :

$$
\log \mathrm{PDW}=0.991 \times \log \mathrm{PD}_{20}+0 \cdot 163
$$

with a correlation coefficient of 0.961 . This calculation implies that PDW:PD $\mathrm{P}_{20}$ is $1 \cdot 46$. In fact the simple comparison of $\mathrm{PC}_{20}$ (or $\mathrm{PD}_{20}$ ) with PCW (or PDW) is not strictly fair as it is possible that wheezing would have been heard at a concentration of methacholine lying between the PCW value and the previous concentration. The calculation of $\mathbf{P C}_{20}$ (or $\mathbf{P D}_{20}$ ) by extrapolation allows for such a situation. If the PCW were reduced to lie between the last two concentrations of the series this would have the effect of subtracting 0.15 from the $\log$ concentration and would reduce the mean difference between them to almost zero such that:

$\mathrm{PCW}=1.08 \times \mathrm{PC}_{20}$ and $\mathrm{PDW}=1.03 \times \mathrm{PD}_{20}$.

In conclusion we believe that the stethoscope can be used to detect wheezing over the trachea as the end point for bronchial provocation testing in young children during the quiet tidal inhalation of methacholine mixtures. In view of the observed mild hypoxia we think it prudent to suggest that the test should be performed by a trained physician, that the concentration of methacholine should be increased by half the usual amount when any of the clinical signs appears, and the test should be stopped if dyspnoea and/or tachypnoea appears, even if no wheeze is audible over the trachea.

1 Cockcroft DW, Killian DN, Mellon JJA, Hargreave FE Bront DW, Killian DN, Mellon JjA, Hargreave FE. Bronchial reactivity to inhaled histamine:
clinical survey. Clin Allergy 1977;7:235-43.

2 Juniper EF, Frith PA, Dunnet C, Cockroft DW, Hargreave FE. Reproducibility and comparison of responses to inhaled histamine and methacholine. Thorax 1978;33:705.

3 Hargreave FE, Ryan G, Thompson NC, O'Byrne PM Latimer $\mathbf{K}$, Juniper GF. Bronchial responsiveness to histamine or methacholine in asthma: measurement and clinical significance. $\mathcal{F}$ Allengy Clin Immunol 1981;68:347.

4 Avital A, Bar-Yishay E, Springer C, Godfrey S. Bronchia provocation tests in young children using tracheal auscultation. $\mathcal{F}$ Pediatr 1988;112:591-4.

5 Mochizuki H, Mitsuhashi M, Tokuyama $K$, Tajima $K$, Morikawa A, Kuroume T. A new method of estimating bronchial hyper-responsiveness in young children. Ann Allengy 1985;55:162-6. 